\title{
Incidental MALT Type Lymphoma Exhibiting Prominent Plasma Cell Differentiation Associated with Hashimoto's Thyroiditis. A Two Case Report
}

\author{
Masaru Kojima · Ken Shimizu · Kazuhiko Shimizu • \\ Nobuhide Masawa
}

Received: 31 July 2008/Accepted: 5 September 2008/Published online: 24 September 2008

(C) The Author(s) 2008. This article is published with open access at Springerlink.com

\begin{abstract}
We present here two cases of incidental extranodal marginal zone B-cell lymphoma of mucosaassociated lymphoid tissue (MALT lymphoma) showing prominent plasma cell differentiation associated with Hashimoto's thyroiditis (HT). Histological examination demonstrated that both lesions exhibited HT including lymphoplasmacytic infiltration with the formation of germinal centers, destruction of the normal thyroid follicular architecture, Hürthle cell changes, and squamous metaplasia. The dominant tumor nodules of both cases contained large, well-circumscribed but unencapsulated aggregation of mature plasma cells and scattered centrocyte-like cells (CCL-cells). Both lesions contained a few lymphoepithelial lesions. Moreover, immunohistochemical study demonstrated that plasma cells and CCL-cells of these two lesions contained monotypic intracytoplasmic
\end{abstract}

M. Kojima $(\square)$

Department of Pathology and Clinical Laboratories,

Gunma Cancer Center Hospital, 617-1, Takabayashinishi-cho,

Ohta 373-8550, Japan

e-mail: mkojima@gunma-cc.jp

\section{K. Shimizu}

Department of Pathology and Clinical Laboratories,

Ashikaga Red Cross Hospital, Ashikaga, Japan

\section{K. Shimizu}

Department of Pathology, Saitama Social Insurance Hospital,

Saitama, Japan

N. Masawa

Department of Anatomic and Diagnostic Pathology,

Dokkyo University School of Medicine, Mibu, Japan kappa light chain. Other small B-cell lymphomas, plasmacytoma and plasmablastic lymphoma were excluded using stains for CD5, CD10, CD23, CD43, CD56. Cyclin $\mathrm{D} 1$, human herpes virus type-8.

Keywords Thyroid gland - MALT type lymphoma . Hashimoto's thyroiditis · Plasma cell granuloma . Immunohistochemistry

\section{Introduction}

Although the pathologic diagnosis of lymphoma traditionally depend on the major criteria of cellular cytological atypia and monomorphism, marginal zone Bcell lymphomas (MZBL) of mucosa associated lymphocytic tissue (MALT) type occasionally lack significant cytological atypia [1]. Moreover, polymorphous lymphoid infiltrate of plasma cells, macrophages and centrocyte like-cells (CCL-cells) is frequently found in MALT type lymphomas [1].

In common with other sites where MALT type lymphomas arise, the thyroid gland is devoid of native lymphoid tissue. Lymphoid tissue acquired in the course of Hashimoto's thyroiditis (HT) bears a close resemblance to MALT. Histologically, HT is characterized by the presence of B-cell follicles, infiltration of thyroid epithelium by B-cells, and plasma cell differentiation. Moreover, in comparison with other MALT type lymphomas, plasma cell differentiation is more prominent in thyroid MALT type lymphoma. As a result, CCL-cells were obscured by numerous mature plasma cells [1-3]. We present here two cases of incidental MALT type lymphoma showing prominent plasma cell differentiation associated with HT. 


\section{Case Report}

\section{Case 1}

An 82-year-old Japanese male was admitted to our hospital with a six-month history of painless left neck mass. Physical examination demonstrated a nodule on the left side of the thyroid gland. Abnormal laboratory test results included an elevated thyroid-stimulating hormone (TSH) level of $73 \mu \mathrm{IU} / \mathrm{ml}$ (normal $<0.4$ ) and a free thyroxine $\left(\mathrm{T}_{4}\right)$ concentration of $0.3 \mathrm{ng} / \mathrm{dl}$ (normal $0.7-1.5$ ). There was no other evidence of disease. Left lobectomy was performed. The left lobe was nodular and firm. A white well demarcated nodule measuring $1 \mathrm{~cm}$ was present in the lower pole of the left lobe (Fig. 1a). The patient remained free of disease on examination two months later.

Case 2

A 78-year-old Japanese female was admitted to our hospital with a painless right neck mass. Physical examination demonstrated a nodule on the right side of the thyroid
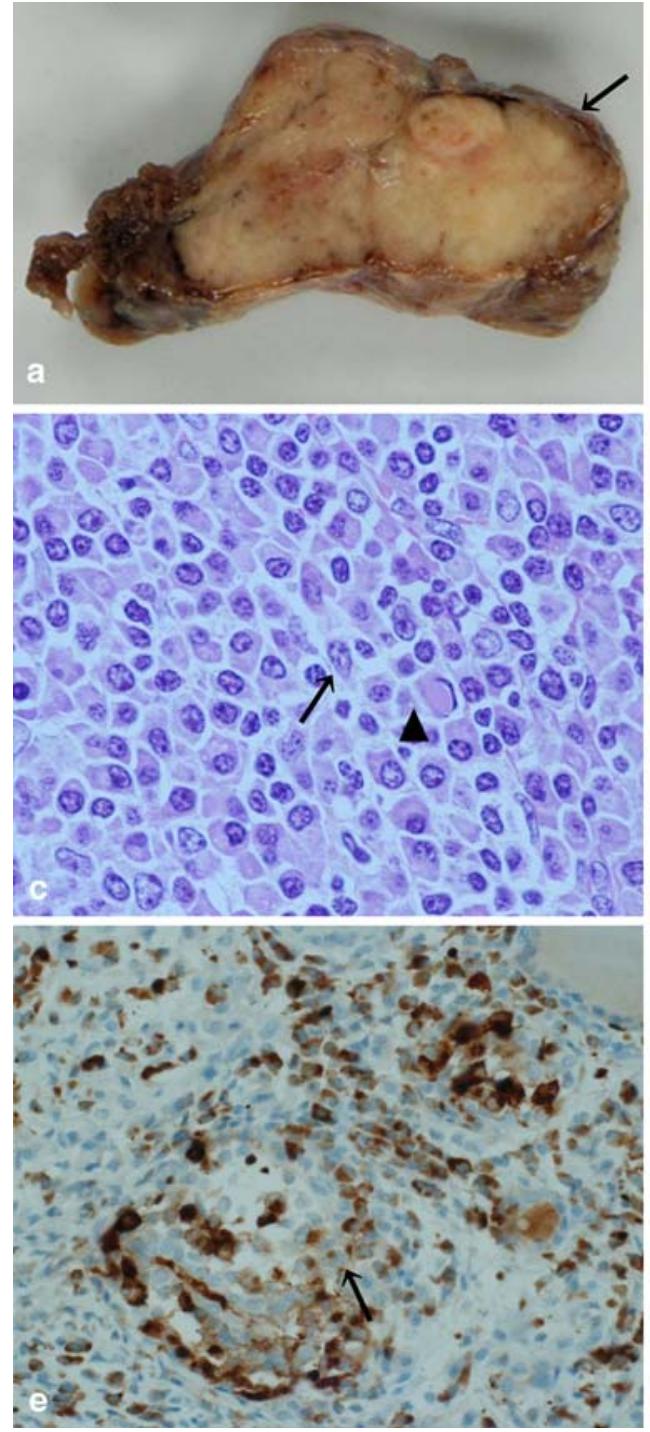

Fig. 1 (a) Cut surface of the resected specimen. A white well demarcated nodule measuring $1 \mathrm{~cm}$ was present in the lower left lobe (arrow) case 1. (b) On low-power field, the dominant nodule was well-circumscribed but unencapsulated (arrow) against background of sclerosis. HE $\times 1.25$ case 1 . (c) On high-power field, the nodule demonstrated numerous mature plasma cells, a few CCL-cells (arrow) and large transformed lymphocytes. Note a Dutcher body (arrow head). HE $\times 100$ case 1 . (d) Numerous mature plasma cells and a few
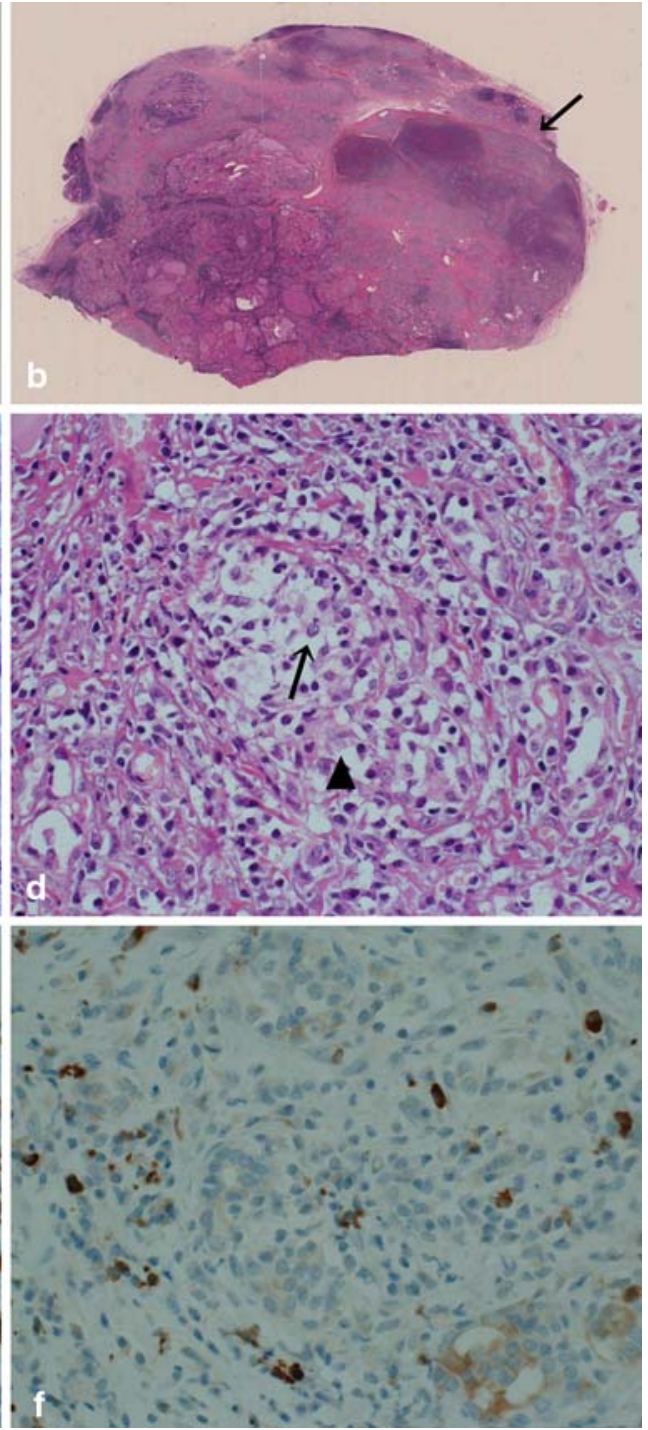

CCL-cells (arrow) infiltrated the thyroid gland acini forming lymphoepithelial lesions. Note a residual thyroid gland epithelium (arrow head). HE $\times 40$ case 2 . Immunohistochemical study demonstrated that numerous neoplastic plasma cells and a portion of CCLcells (arrow) were kappa light chain positive (e) but lambda light chain negative. Note a few polyclonal plasma cells in the back ground (f) $\times 40$ case 2 
gland. Abnormal laboratory findings included positivity on microsome test $(\times 6400)$. There was no other evidence of disease. Right lobectomy was performed. The right lobe was nodular and firm. A $1.5 \mathrm{~cm}$ white well demarcated nodule was present in the lower pole of the lobe. The patient remained free of disease on examination 18 months later.

\section{Materials and Methods}

Both the clinical findings and paraffin blocks were available for both cases. The tissue specimens were fixed in formalin solution, routinely processed and embedded in paraffin. For light microscopic examination, the sections were stained with hematoxylin-eosin (HE).

Immunohistochemical studies were performed using the Ventana automated (BenchMarkTM) stainer according to the manufacturer's instructions. The panel of antibodies included human immunoglobulin light chains (kappa and lambda) (Novocastra, Newcastle, UK), PS-1 (CD3; Immunotech, Marseille, France), 4C7 (CD5; Novocastra), 56C6 (CD10; Novocastra), L26 (CD20; Dako A/S, Glostrup, Denmark), 1B12 (CD 23; Novocastra), DFT-1 (CD43; Dako), 1B16 (CD56; Novocastra), 5A4 (p80; Novocastra), SP4 (Cyclin D1; Nichirei Co., Tokyo, Japan), 124 (bcl-2; Dako), AE1/3 (cytokeratin; Dako) and 137B1 (human herpes virus type-8 [HHV-8], Novocastra). Sections with known reactivity for the antibodies assayed served as positive controls and the sections treated with normal rabbit- and mouse serum served as negative controls.

In situ hybridization (ISH) with Epstein-Barr virus (EBV)-encoded small RNA (EBER) oligonucleotides was performed to test for the presence of EBV small RNA in formalin-fixed paraffin-embedded sections using a Ventana automated (BenchMarkTM) stainer.

\section{Results}

Both patients showed essentially similar histological and immunohistochemical findings. Histological examination demonstrated that both lesions exhibited HT including lymphoplasmacytic infiltration with the formation of germinal centers, destruction of the normal thyroid follicular architecture, Hürthle cell changes, and squamous metaplasia. Focal fibrosis was also noted. The dominant nodule in both cases contained large, well-circumscribed but unencapsulated aggregation of mature plasma cells against a background of sclerosis (Fig. 1b). In case 1, a portion of the mature plasma cells demonstrated intranuclear inclusions (Dutcher body) (Fig. 1c). Scattered small-to-medium lymphocytes and large lymphoid cells were also intermingled with plasma cells. In both lesions, mediumsized lymphocytes had round or slightly indented nuclei with small conspicuous nucleoli and a moderate amount of clear cytoplasm (centrocyte-like cells; CCL-cells) (Fig. 1c). In the background, there were a few remnants of destroyed thyroid follicles. Numerous mature plasma cells and a few CCL-cells infiltrated the thyroid gland acini forming lymphoepithelial lesions (LeLs) (Fig. 1d). However, both lesions contained only a few LeLs. A few remnants of residual lymphoid follicles were also noted.

The majority of mature plasma cells and a portion of CCL-cells in the main nodules showed intracytoplasmic kappa light chain (Fig. 1e, f). However, the plasma cells outside the main nodules showed a polytypic nature.

CCL-cells were also CD 20 positive. However, there were no CD5, CD10, CD23, CD43, Cyclin D1, HHV-8 positive B-cells in either lesion. There were no CD56 positive plasma cells in either lesion. Other small B-cell lymphomas, plasmacytoma and plasmablastic lymphoma were excluded using stains for CD5, CD10, CD23, CD43, CD56. Cyclin D1, HHV-8 [4]. CD23 immunostain demonstrated a few residual follicular dendritic cell network colonized by the neoplastic plasma cells and CCL-cells. LeLs were also highlighted by cytokeratin immunostaining. There were no Epstein-Barr virus (EBV)-encoded small RNA (EBER) positive cells in any of the lesions on in situ hybridization using a Ventana automated (BenchMarkTM) stainer.

The plasma cells outside the main nodules showed polytypic nature.

\section{Discussion}

Hussung et al. [5] reported five cases of extramedullary plasmacytoma that showed characteristic histological findings of MZBL, including the presence of a marginal zone distribution pattern, CCL-cells, reactive lymphoid follicles with or without follicular colonization and LeL at sites where epithelium was present. Based on these observations, they suggested that a portion of extramedullary plasmacytoma can be regarded as an extreme plasmacytic differentiation of MZBCL [5]. In both lesions reported here, numerous mature plasma cells and a few CCL-cells contained monotypic intracytoplasmic kappa light chain. Moreover, immunostain highlighted a few LeLs and remnants of follicular dendritic cell network colonized by the neoplastic plasma cells and CCL-cells. As Hussung et al. [5] suggested, both of our cases would best be classified as MZBCL of MALT type showing prominent plasma cell differentiation.

The present two cases should be differentiated from various benign and plasma cell lesions that affect thyroid 
gland [6]. Among these, inflammatory pseudotumor of plasma cell variant (plasma cell granuloma; PCG) appears to be the most important lesion in the differential diagnosis. [6-9]. PCG is a non-neoplastic proliferation of plasma cells within a fibrous stroma with unknown etiology. PCG of the thyroid gland is very rare [7-9]. However, PCG of the thyroid gland is occasionally associated with HT [7-9]. Histologically, there is a diffuse and focally nodular infiltration of numerous mature plasma cells intermixed with lymphocytes and surrounded by fibrous tissue [7-9]. Moreover, squamous metaplasia with lymphoplasmacytic infiltration somewhat resembling LeL in MALT type lymphoma was noted. Overall histomorphological findings of the present two cases were similar to those of PCG associated with HT. However, immunohistochemical study demonstrated the polytypic nature of plasma cells in PCG, whereas plasma cells of both lesions reported here, demonstrated monotypic intracytoplasmic kappa light chain [7-9].

Thyroid gland involvement of multiple myeloma is ruled out by laboratory and clinical examination [7]. Moreover, there were no CD56 positive plasma cells in any of the lesions [10]. Extramedullary plasmacytoma is another differential diagnostic problem. However, there were no CD20 positive tumor cells in the extramedullary plasmacytoma, whereas both lesions in this series contained a few CD20 positive CCL-cells.

Previously, Hyjek and Isaacson [2] reported that analysis of thyroid glands from 236 cases of surgically treated HT demonstrated five cases $(2.1 \%)$ of incidental MALT type lymphoma. We also found two cases $(3.8 \%)$ of incidental MALT type lymphoma showing prominent plasma cell differentiation among 53 cases of surgically treated HT treated by one of the authors (M. K) between 1982 and 2007. As Hyjek and Isaacson [2] indicated, given the indolent nature of thyroid MALT type lymphoma, as defined by light chain restriction of the B-cells and plasmacytic infiltrate arising in HT, it is conceivable that the true incidence of thyroid MALT type lymphoma may be much higher than recognized.

Open Access This article is distributed under the terms of the Creative Commons Attribution Noncommercial License which permits any noncommercial use, distribution, and reproduction in any medium, provided the original author(s) and source are credited.

\section{References}

1. Isaacson PG, Norton AJ. Extranodal lymphomas. Edinburgh, United Kingdom: Churchill Livingstone; 1994.

2. Hyjek E, Isaacson PG. Primary B cell lymphoma of the thyroid and its relationship to Hashimoto's thyroiditis. Hum Pathol. 1988;19:1315-26. doi:10.1016/S0046-8177(88)80287-9.

3. Derringer GA, Thompson LDR, Frommelt RA, et al. Malignant lymphoma of the thyroid gland. A clinicopathologic study of 108 cases. Am J Surg Pathol. 2000;24:623-39. doi:10.1097/00000478200005000-00001.

4. Feller AC, Diebold J. Histopathology of nodal and extranodal non-Hodgkin's lymphomas. Berlin, Germany: Springer; 2004.

5. Hussong JW, Perkins SL, Schnitzer B, et al. Extramedullary plasmacytoma. A form of marginal zone cell lymphoma? Am J Clin Pathol. 1999;111:111-5.

6. Kovacs CS, Mant MJ, Nguyen GK, et al. Plasma cell lesions of the thyroid: report of a case of solitary plasmacytoma and a review of the literature. Thyroid. 1994;4:65-71.

7. Mugler K, Gaido MD, Ryder J, et al. Plasma cell granuloma of the thyroid with Hashimoto's thyroiditis: report of a rare case. Ear Nose Throat J. 2003;82:64-6.

8. Kriegel L, Guetgemann I, Zhou H. Plasma cell granuloma of the thyroid gland mimicking carcinoma: a case report and review of the literature. Pathol Res Pract. 2007;203:813-7. doi:10.1016/ j.prp.2007.07.005.

9. Deniz K, Ptiroĝlu TR, Okren T. Plasma cell granuloma of the thyroid. APMIS. 2008;116:167-72. doi:10.1111/j.1600-0463. 2008.00827.x.

10. Kremer M, Ott G, Nathrath M, et al. Primary extramedullary plasmacytoma and multiple myeloma: phenotypic differences revealed by immunohistochemical analysis. J Pathol. 2005;205: 92-101. doi:10.1002/path.1680. 